(A)

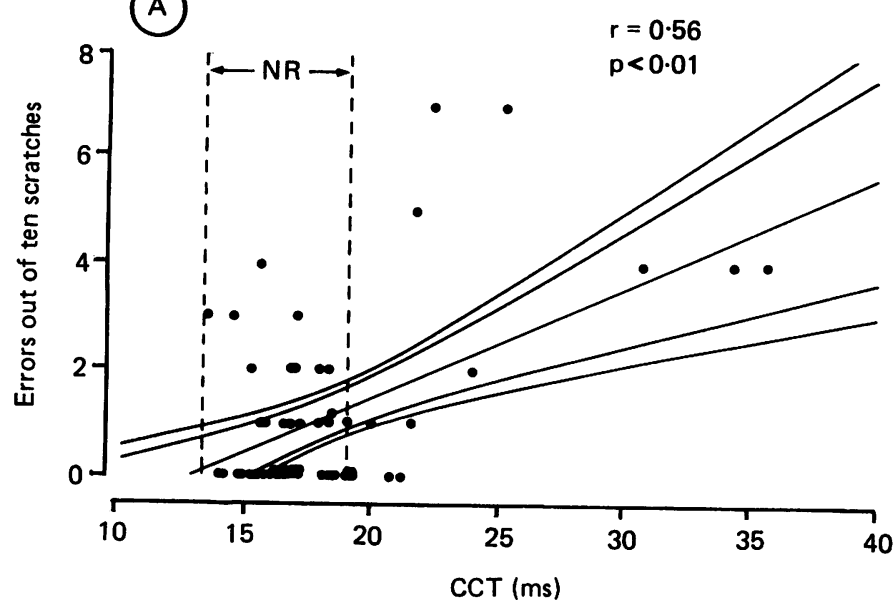

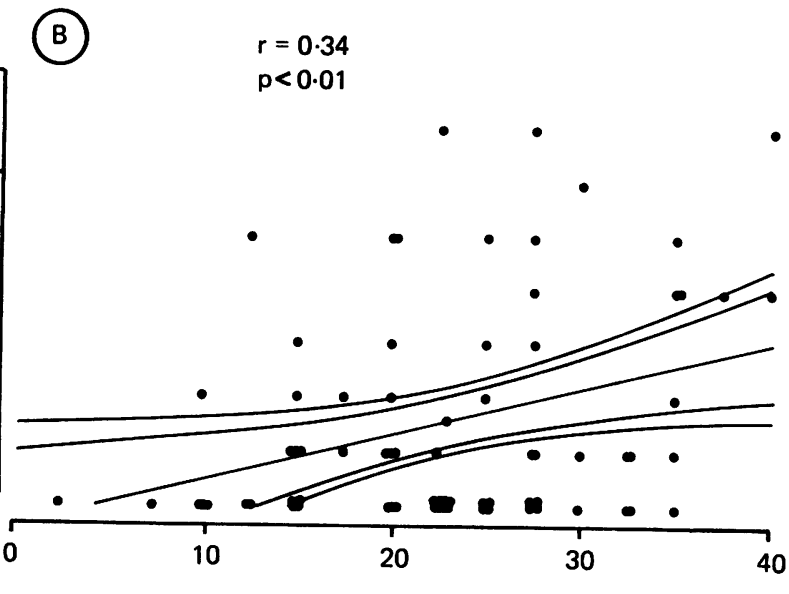

VPT $(125 \mathrm{~Hz})(\mathrm{dB})$

Number of errors in the scratch test for central conduction time (CCT) (a) and vibration perception threshold (VPT) (b) Normal range (NR) indicates the mean $3 S D$ of the normal value. The straight line shows the regression line, and the inner and outer curves represent the $99 \%$ and $95 \%$ confidence
limits, respectively.

multiple sclerosis, six with spinocerebellar degeneration, two with hereditary spastic paraplegias, two with ossifications of the posterior longitudinal ligament, two with cerebrovascular diseases and one patient with thoracic spinal cord tumour. None were complicated by peripheral neuropathy. A uniform random binary number sequence of 10 vertical $2 \mathrm{~cm}$ scratches was performed over the anterior aspect of the shin with the sharp margin of a paper clip. The subjects were asked to state whether the direction of the scratch was "up or down", and the number of errors was assessed. Scalp N/P 37 and $\mathrm{N} 19$ over the $\mathrm{T} 12$ spinous process to electric stimulation of the posterior tibial nerve were recorded by means of a Medelec MS-20 (UK), and the central conduction time (CCT; N/P37-N19) was evaluated. Vibration perception of the big toe was measured at $63 \mathrm{~Hz}, 125 \mathrm{~Hz}$ and $250 \mathrm{~Hz}$ by Rion vibrometer (Japan). The subjects were "blind" to the changes being made in stimulus intensity, which was increased stepwise every three seconds from $-10 \mathrm{~dB}$ at $2 \cdot 5 \mathrm{~dB}$ intervals until it was noticed by the subject. The vibration perception threshold (VPT) was defined as the lowest stimulus intensity to be noted.

The number of errors in the scratch test was found to be significantly correlated not only with the CCT $(p<0.01, r=0.56$, figure a) but also with the VPTs at $63 \mathrm{~Hz}$ $(\mathrm{p}<0.01, \quad \mathrm{r}=0.34), \quad 125 \mathrm{~Hz} \quad(\mathrm{p}<0.01$, $r=0.34$, figure $b)$ and $250 \mathrm{~Hz}(\mathrm{p}<0.05$, $r=0 \cdot 27)$. These results agree that the scratch test, SEP and VPT are examinations commonly reflecting posterior column function.

The scratch test is recommended as a simple and yet reliable clinical neurological examination for detecting posterior column dysfunction.

$$
\begin{array}{r}
\text { YUMIKO MOTOI } \\
\text { HIROYUKI MATSUMOTO } \\
\text { YUH KANESHIGE } \\
\text { SUSUMU CHIBA } \\
\text { Department of Rehabilitation and Neurology, } \\
\text { Sapporo Medical College, } \\
\text { South 1 West 16, Chuou-Ku, } \\
\text { Sapporo 060, fapan. }
\end{array}
$$

Correspondence to: Dr Motoi

1 Hankney GJ, Edis R. The utility of testing tactile perception of direction of scratch as a sensitive clinical sign of posterior column dysfunction in spinal cord disorders. 7 Neurol Neurosurg Psychiatry 1989;52:395-8.

\section{Seventh nerve palsy as a false localising sign}

Benign intracranial hypertension (BIH) usually produces a clinical picture of headache, visual disturbances and bilateral papilloedema. Abducens nerve palsies have been reported in between $10-30 \%$ of cases. Other cranial nerve palsies have rarely been reported in this condition ${ }^{1-5}$ and those that have occurred were nearly always in children. One case of facial diplegia occurring in an adult with this condition has been documented. ${ }^{6}$ We report a patient with BIH who presented with bilateral sixth nerve palsies and a right sided seventh nerve palsy all of which resolved after a lumbar puncture.

A twenty five year old obese woman on the contraceptive pill presented with a three week history of bifrontal headaches, nausea and vomiting. The headache was not made worse by coughing or stooping and neither was it relieved by analgesics. One week before admission the patient developed diplopia on horizontal gaze and visual obscuration. Examination revealed mild bilateral sixth nerve palsies and a right sided facial nerve palsy of lower motor neuron type with reduced blink reflex. The visual acuity was 6/6-2 on the right and 6/5-1 on the left. The blind spots were enlarged but the visual fields were otherwise normal. Marked bilateral papilloedema was observed. An otological examination was normal. A CT head scan, including a contrast examination, was normal. Lumbar puncture revealed clear and colourless CSF with an opening pressure of $300 \mathrm{~mm}$ CSF. The fluid was acellular with protein of $230 \mathrm{mg} / 1$ and a glucose of 4.0 $\mathrm{mmol} / \mathrm{l}$ (plasma glucose $5.2 \mathrm{mmol} / \mathrm{l}$ ), Gram stain and cytology for malignant cells were both negative. The following investigations were normal : CXR, FBC, ESR, ANF, VDRL, clotting studies, lupus anti-coagulant, fibrinogen level, immunoglobulins, C3,C4, serum oestriol, androstenedione, serum DHA - sulphate, LH and FSH. On the day following lumbar puncture, the diplopia had resolved and facial weakness improved. By the second day, the cranial nerves examination was normal except for papilloedema. The patient was started on a weight reducing diet and has required no further treatment. On review six weeks after discharge, the visual acuity was $6 / 4$ bilaterally and mild papilloedema was present.

Identifying a neurological sign as being falsely localising rests on two important considerations. Firstly, that an accurate knowledge of the anatomy is attained and secondly, that the sign itself must arise in an anatomical area that is remote from the site of the original pathology. A sixth nerve palsy is a classic example in patients with raised intracranial pressure from a brain tumour distant from the course of the nerve. The long intracranial course of the abducens nerve is thought to be responsible for its predilection compared to other cranial nerves. However, Collier favours an alternative explanation based on the direction in which the nerve emerges from the brainstem. The abducens nerve emerges in a straight forward direction, whilst all other cranial nerves emerge transversely or obliquely. Therefore, backward displacement of the brainstem by an intracranial space occupying lesion would exert its maximum effect on the sixth nerve. ${ }^{7}$ Either way the patho-physiological mechanism is thought to involve displacement of the brain by enlarging intracranial mass and traction upon cranial nerves. False localisation from other cranial nerve palsies have also been described. ${ }^{78} \mathrm{BIH}$ offers a very good model to study the effect of raised pressure without focal mass effect suggesting that the cranial nerve palsies could be the result of general pressure related effect without implying a specific directional intracranial pressure forces. BIH was first described by Quincke in 1893 . $^{\circ}$ At that time otitis media was thought to be the most common aetiology and there has been renewed interest in sinus occlusion in the genesis of BIH. ${ }^{10}$ Many other mechanisms have been implicated including obesity $^{11}$ and the contraceptive pill ${ }^{12}$ both of which were involved in our patient.

Whilst abducens nerve palsies are not uncommonly seen as a false localising sign of 
raised intracranial pressure, ${ }^{13}$ facial palsies are distinctly uncommon in this setting. A case of BIH with facial diplegia has been reported but was thought to be the result of non specific pressure related phenomenon displacing and stretching the seventh nerves. ${ }^{\circ}$ One report mentions three children with BIH and an associated seventh nerve palsy, however, the weakness in all cases took over five weeks to resolve and was attributed to an associated Bell's palsy. ${ }^{3}$ In 18 children with BIH only one had facial weakness ${ }^{4}$ and a larger series of 79 children reported facial palsy in only three cases. ${ }^{14}$ Given the rapid resolution of cranial nerve palsies following lumbar puncture, the most plausible explanation is that seventh nerve palsy can occur, albeit rarely, as a false localising sign of raised intracranial pressure. Other focal neurological signs with long tract involvement have been attributed to BIH, ${ }^{15}$ but it must be stressed that in this and all cases of atypical BIH close follow up is essential.

\section{DAVIE \\ P KENNEDY \\ Wessex Neurological Centre, Southampton General Hospital, Southampton, UK}

Correspondence to: Dr Katif, Department of chapel, London E1 IBB, UK.

1 Rush JA. Pseudoproblems, Pseudotumour cerebri. Br 7 Hosp Med 1983;29:320-5.

2 McCammon A, Kaufman HH, Sears S. Transient oculomotor paralysis in pseudotumor sient oculomotor paralysis in ps
cerebri. Neurology $1981 ; 31: 182-4$

3 Chutorian AM, Gold AP, Braun CW. Benign intracranial hypertension and Bell's palsy. NEFM 1977;296:1214-5.

4 Grant DN. Benign intracranial Hypertension: A review of 79 cases in infancy and childhood. Arch Dis Child 1971;46:651-5.

5 Halpern JI, Gordon WH. Trochlear nerve palsy as a false localising sign. Ann Ophthalmo 1981;13:53-6.

6 Kiwak KJ, Levine SE. Benign intracranial Hypertension and facial diplegia. Arch Neurol 1984;41:787-8.

7 Collier JS. The false localizing signs of intracranial tumours. Brain 1904;27:490-508.

8 Gassel MM. False localizing signs. Arch Neurol 1961:4:526-54.

9 Quincke H. Ueber meningitis serosa. Sammlung Klinische Vortaage 1893;67(Innere medizin 23):655.

10 Pasquale LR, Moster ML, Schmaier A. Dural sinus thrombosis with abnormalities of protein $\mathrm{S}$ and fibrinogen. Arch Ophthalmo 1990;108:644

11 Boddie HG, Banna M, Bradley WG. Benign Intracranial Hypertension. A survey of the clinical and radiological features and long term prognosis. Brain 1974;97:313-26.

12 Bulens C, DeUries AEJ. Benign intracrania Hypertension. A retrospective and follow up study. $\mathcal{F}$ Neurol Sci 1979;40:147-57.

13 Johnston I, Paterson A. Benign intracranial hypertension. Brain 1974;97:289-300.

14 Hagberg B, Sillanpaa M. Benign intracranial hypertension (Pseudotumour cerebri). Acta hypertension (Pseudotumour
Pediatr Scand 1970;59:328-39.

15 Zachariah SB, Jimenez L, Zachariah B, Prockop LD. Psuodotumour cerebri with focal neuroLD. Psuodotumour cerebri with focal neuro-
logical deficit. $\mathcal{I}$ Neurol Neurosurg Psychiatry 1990;53:360-1.

Lumbosacral meningoradiculitis associated with Chlamydia pneumoniae infection

Infections due to Chlamydia pneumoniae have recently been identified ${ }^{\prime 2}$ and usually give rise to oropharyngeal and pulmonary complications. Neurological manifestations have not, to our knowledge, been described. We
Table Antibody levels in serum specimens and CSF to Chlamydia (Chl) species by indirect microimmunofluorescence test

\begin{tabular}{|c|c|c|c|c|c|c|}
\hline \multirow{2}{*}{$\begin{array}{l}\text { Dates } \\
\text { Day/month/year }\end{array}$} & \multirow[b]{2}{*}{ Specimens } & \multicolumn{2}{|c|}{ Chl pneumoniae } & \multicolumn{2}{|c|}{ Chl trachomatis } & \multirow{2}{*}{$\frac{\text { Chl psittaci }}{\text { Total }}$} \\
\hline & & Total & IgM & Total & IgM & \\
\hline $\begin{array}{l}08 / 09 / 90 \\
08 / 09 / 90 \\
25 / 09 / 90 \\
30 / 01 / 91\end{array}$ & $\begin{array}{l}\text { Serum } \\
\text { CSF } \\
\text { Serum } \\
\text { Serum }\end{array}$ & $\begin{array}{c}128 \\
16^{\star} \\
128 \\
64\end{array}$ & $\begin{array}{r}64 \\
<2 \\
32 \\
<16\end{array}$ & $\begin{array}{l}64 \\
<2 \\
64 \\
32\end{array}$ & $\begin{array}{r}16 \\
<2 \\
<16 \\
<16\end{array}$ & $\begin{array}{l}32 \\
\text { ND } \\
32 \\
\text { ND }\end{array}$ \\
\hline
\end{tabular}

^Ratio serum/CSF $=8$

ND $=$ Not Done

report the case of a child presenting with lumbosacral meningoradiculitis.

A nine year old child without a previous medical history presented with a cough and rhinitis beginning on the 21 August 1990 and lasting six days. His temperature had not been recorded. He was treated initially with amoxicillin which was stopped on the 27 August due to an erythematous macular rash on the knees and thighs. On the 31 August the patient complained of weakness of the lower extremities, predominantly the hips and thighs, resulting in a waddling gait and an inability to rise from a crouching position. Neurological evaluation on the 8 September revealed significant back stiffness, bilateral Lassegue's sign, motor weakness of the lower extremities, especially affecting flexion and adduction of the thighs, less so the flexors and extensors of the legs. Knee jerk was absent on the right, diminished on the left. Ankle jerks were intact. Plantar responses were flexor. There were no objective sensory deficits nor sphincter dysfunction. Lumbar puncture (8 September) obtained clear fluid containing 6 lymphocytes $/ \mathrm{mm}^{3}, 97 \mathrm{mg} \%$ protein and normal glucose. Saccoradiculography was normal. Electromyography of the lower limbs (10 September) was normal as were nerve conduction velocities. Clinical recovery was gradual and almost complete by six months.

Acute and convalescent serology taken 16 days apart excluded the following infectious agents: Mycoplasma pneumoniae, Legionella pneumophila, Rickettsia burnetti, conori and mooseri, herpes simplex virus, herpes zoster virus, Epstein-Barr virus, cytomegalovirus, measles, mumps, adenovirus, enterovirus (Echoviruses 7, 25, 30, 33; Coxsackieviruses A9 and B2). Indirect immunofluorescence techniques $^{3}$ were used to determine serum and CSF antibodies against various Chlamydia species (table). These showed a recen infection with Chlamydia pneumoniae, indicated by an elevated titre of serum IgM which disappeared by the fifth month. Furthermore, whereas the serum/CSF antibody ratio for measles and herpes zoster viruses was $1: 128$, it was $1: 8$ for $C$ pneumoniae, suggesting a local synthesis of antibodies.

Our report concerns a case of localised meningoradiculitis, especially in the proximal lower extremities, associated with an infection with $C$ pneumoniae. The negativity of all other serological tests and the existence of intrathecally secreted antibodies against $C$ pneumoniae are in favour of this being the causative agent of the neurological presentation. The presence of IgM proves the recent nature of the infection. ${ }^{4}$ The other Chlamydia species have been implicated in rare cases of CNS complication. ${ }^{56}$ The absence of any other reports of neurological complications due to $C$ pneumoniae is probably due to the fact that identification methods have only recently been available.

\section{MNTHEL Department of Neurology,
CHU de Saint-Etienne, Hôpital Bellevue, Saint-Etienne
B POZZETTO OG GAUDIN Virology Laboratory,
CHU-de Saint-Etienne, Hôpital Nord,
42277 Saint-Priest-en-farez F LUCHT Department of Infectious Diseases, Department of Injectious Diseases,
CHU de Saint-Etienne, France}

1 Campbell LA, Kuo CC, Grayston JT. Characterization of the new Chlamydia agent, TWAR, as a unique organism by restriction endonuclease analysis and DNA-DNA hybridization. $f$ Clin Microbiol 1987;25: 1911-6.

2 Grayston JT, Kuo CC, Campbell LA, Wang SP. Chlamydia pneumoniae sp. nov. for Chlamydia sp. strain TWAR. Int $\mathcal{f}$ Syst Bacteriol 198. strain TW 39:88-90.

3 Wang SP, Grayston JT. Human serology in Chlamydia trachomatis infection with microChlamydia trachomatis infection with micro-
immunofluorescence. $\mathcal{f}$ Infect Dis 1974; immunofluores

4 Wang SP, Grayston JT. Microimmunofluorescence serological studies with the TWAR organism. In: Oriel JD, Ridgway G, Schachter J, Taylor-Robinson D, Ward M, eds. Chlamydial infections. Cambridge: Cambridge University Press, 1986:329-32.

5 Myrhe EB, Mardh PA. Chlamydia trachomatis infection in a patient with meningoencephalitis. New Engl $₹$ Med 1981;304;910-1.

6 Reis J, Le Faou A, Levy F, Kapfer MT, Gut JP. Forme confusionnelle d'une encéphalite Chlamydia psittaci. Intérét diagnostique de la Chlamydia psittaci. Interet diagnostique de la 14:87-9.

Postoperative fourth ventricle tension pneumocephalus

We report an unusual case of postoperative tension pneumocephalus (PTP) after posterior fossa surgery carried out with the patient in the sitting position.

A 65 year old man was admitted to our hospital in May 1987 because of dizziness, vertigo, vomiting and diplopia. He had right extra motor ocular muscle paresis and right sided ataxia. CT showed a haematoma in the right hemisphere cerebellar. The clot was larger than $3 \mathrm{~cm}$, but there was no hydrocephalus (figure 1a). General anesthesia was administered via endotracheal intubation and consisted of a mixture of $60 \%$ nitrous oxide oxygen and halothane. He was placed in the sitting position. Hyperventilation and furosemide were used to reduce brain bulk. A right suboccipital craniectomy was per- 